\title{
UM RECORTE SOBRE O FAZER FILOSÓFICO NO BRASIL: EDUCAÇÃO, AUTONOMIA E CONSCIENTIZAÇÃO
}

\section{Neyha Guedes Dariva*}

\begin{abstract}
Resumo: Este trabalho tem como objetivo traçar um recorte da filosofia brasileira, no contexto das pedagogias críticas, em relação a uma forma tradicional do fazer educacional. Para isso, destacamos as noções básicas da tradição filosófica que são caras à filosofia nacional, bem como estabelecemos suas inovações e preocupações pontuais, apresentando um pensamento filosófico local, situado dentro de nossas próprias temáticas e necessidades enquanto país. A educação ganha centralidade nesta discussão, enquanto ferramenta fundamental para a melhoria da condição social. A filosofia produzida no Brasil, por fim, merece destaque por situar-se dentro de nossas próprias concepções de mundo $e$ dialogar com nossos próprios processos históricos.
\end{abstract}

Palavras-chave: Filosofia; Filosofia brasileira; Conscientização; Autonomia; Educação.

Resumen: Este trabajo tiene como objetivo trazar un recorte de la filosofía brasileña, en el contexto de las pedagogías críticas, en relación a una forma tradicional del quehacer educativo. Para ello, destacamos las nociones básicas de la tradición filosófica que son caras a la filosofía nacional, bien como establecemos sus innovaciones y preocupaciones puntuales, presentando un pensamiento filosófico local, situado dentro de nuestras propias temáticas y necesidades en cuanto país. La educación gana centralidad en esta discusión, en cuanto herramienta fundamental para la mejora de la condición social. Para finalizar, la filosofía producida en Brasil, merece destaque por situarse dentro de nuestras propias concepciones de mundo, y dialogar con nuestros propios procesos históricos.

Palabras claves: Filosofía; Filosofía brasileña; Concientización; Autonomía; Educación.

\section{Educação e Filosofia}

Quando tratamos do pensamento filosófico brasileiro a questão pertinente que se apresenta pode evocar aos velhos e novos problemas da filosofia estrangeira. É sabido que nossa constituição nesta área de estudo esteve sempre atrelada à modelos europeus do fazer filosófico. De fato, a filosofia ocidental é fortemente marcada pela narrativa europeia, com as problemáticas propostas desde a Grécia Antiga até os dias atuais. Há quem garanta, por exemplo, que toda a filosofia desde Platão é um emaranhado de ideias $e$ interpretações nascidas de suas discussões fundamentais, de suas bases teóricas

\footnotetext{
* Mestre em Educação pela Universidade Federal de Santa Maria (UFSM), sob orientação da $\operatorname{prof}^{\mathrm{a}} \mathrm{dr}^{\mathrm{a}}$. Elisete Medianeira Tomazetti, e Licenciada em Filosofia pela Universidade Federal da Fronteira Sul (UFFS). Contato: neyhadariva@gmail.com.
}

e de suas dúvidas constituintes. O que leva a um fazer filosófico traçado e retilíneo, desde o centro de uma cultura específica que molda a atividade de nossa reflexão até a atualidade. Indiferente da concordância ou não desta análise, podemos admitir que dentro de nossa própria constituição nacional a filosofia esteve sempre empregada nos moldes de uma padronização de pensamento desde o efetivado no continente europeu. Assim, a filosofia por aqui pode ser taxada como sendo desconectada do pensar de nossa própria realidade e sem identidade própria. Mas será que essa afirmação faz jus com nossa produção nacional?

Uma faceta filosófica que por muito tempo fora considerada marginal nas temáticas e reflexões da área pode ser a chave para entendermos de que maneira uma filoso- 
fia nacional se aperfeiçoou, tornando-se de vital importância em nosso cenário atual. A educação, seja em seu modelo antigo ou contemporâneo, sempre manteve no seio de suas preocupações assuntos conectados com o conhecimento filosófico, uma vez que, todo repasse ou construção do conhecimento considera o acumulado das gerações passadas e se envolve com as questões pertinentes de seu próprio contexto histórico. A reflexão filosófica, acompanhando as demandas $e$ transformações sociais, interessou-se pela educação, principalmente na modernidade $e$ nas filosofias da educação pós $2^{\mathrm{a}}$ guerra, numa espécie de aposta no indivíduo, em ambos os contextos. No primeiro caso, o advento da modernidade trouxe consigo novas aspirações sociais e, portanto, novas demandas também no âmbito educacional. Os modelos medievais de pensamento foram ultrapassados por uma visão de liberdade que estava de todo conectada com as novas descobertas científicas e com essa maneira de adquirir conhecimentos e comprovar teorias. No segundo caso, a educação contemporânea pós $2^{a}$ guerra precisava lidar com uma análise filosófica preocupada com as questões da crueldade e de sua missão máxima, a saber, a de equipar os indivíduos de uma capacidade de reflexão humana, para evitar os horrores do extermínio em massa e da frieza. Este foi o ponto central da teoria crítica da escola de Frankfurt, por exemplo. Em ambos os casos, os conceitos de autonomia e emancipação se apresentam como compondo a ferramenta necessária desta aposta no indivíduo.

A educação brasileira também entra nesta esteira de pensamento filosófico, mas erra quem acredita que foi com intuito de apenas reproduzir os conhecimentos e conceitos da filosofia europeia. Sua contribuição é garantida na tentativa de resolução prática e teórica de problemas e demandas locais, de uma filosofia política competente e audaciosa dentro do próprio país. Primeiro, é verdade, a filosofia educacional brasileira adere às transformações de cunho epistemológico da modernização mundial; o positivismo e a expansão da mentalidade científica passa a ditar as novas estruturas educacionais, lidando com conceitos como os de eficácia e de técnicas. Mas a inovação deste campo do conhecimento viria a partir, justamente, de um ideal educativo para além destas definições. Tanto acompanhando às críticas contemporâneas da filosofia europeia, quanto inovando em âmbito de visão regionalizada. Neste texto traremos algumas das propostas de dois autores brasileiros de suma importância filosófica: Paulo Freire e Dermeval Saviani. Seus pensamentos e críticas no campo educacional inserem-se na própria história da educação brasileira bem como na de uma produção filosófica nacional. Para ambos, o fazer filosófico objetiva a prática transformadora que deve mobilizar a prática social na atualidade. Assim, suas teorias extrapolam o campo teórico lidando com problemas práticos de uma educação voltada para objetivos específicos.

\section{Entre teoria e prática: contextualizando a base teórica \\ O século XIX é marcado pela figura} de alguns ilustres pensadores que movimentaram as teorias políticas deste período. Foi Marx (1818-1883), autor marcante neste contexto, quem analisou a história da humanidade, apontando no cerne da organiza- 
ção social, um novo elemento estruturante: as relações materiais. Em sua conhecida teoria acerca do materialismo histórico dialético, o filósofo destaca as relações econômicas como a principal linha de análise para a compreensão histórica. A saída do sistema feudal de produção, para dar lugar a uma nova forma de relação econômica, trouxe consigo novos olhares em relação à própria epistemologia. A dialética Hegeliana (17701831) apontava para uma constante evolução humana, mas marcava como ponto determinante a figura do Zeitgeist. Diferente de Hegel, Marx não encontrou na figura de líderes evoluídos a característica fundamental para as transformações históricas. Apontou, antes, para o próprio sistema das relações econômicas, com sua lógica operante de saturação e, posterior, ruptura. As desigualdades e a dominação estariam no centro desta necessidade de mudança. Em cada momento histórico podemos observar o levante dos oprimidos em prol da mudança de sua condição desigual. A práxis ${ }^{3}$ estaria assim garantida, segundo Marx, movimentando uma correlação entre a teoria - importante para o conhecimento - e a prática - transformadora no âmbito social.

\footnotetext{
${ }^{2}$ Termo em alemão que se refere a um "espírito da época".

${ }^{3}$ Conceito de origem grega que corresponde a uma atividade prática em oposição à teórica. Marx, porém, extrapolou os limites da noção grega atribuindo novas características ao conceito. Para o autor a prática é determinante para a teoria, estabelecendo uma correlação de dependência entre ambas. Sua posição é justificada segundo sua noção de trabalho e de transformação da natureza. Segundo a definição de Bettomore, em seu Dicionário do Pensamento Marxista, "o conceito de práxis torna-se o conceito central de uma nova filosofia, que não quer permanecer como filosofia, mas transcender-se tanto em um novo pensamento metafilosófico como na transformação revolucionária do mundo" (2012, p. 433).
}

As teorias marxistas conquistaram adeptos que pensaram suas concepções $e$ propostas para além do campo econômico, adentrando também o pensamento educacional. Gramsci (1891-1937), por exemplo, critica a dissonância social, encarando a escola como cerne desta desigualdade. Para o autor, a educação deve abandonar sua característica de reprodutora fiel das desigualdades sociais, deixando de segregar uma área de formação meramente braçal e outra intelectual. A essa dicotomia praticada na educação de seu tempo, Gramsci instaurou seu objeto de crítica. Segundo o filósofo, era preciso reivindicar ao proletariado o direito à cultura, estabelecendo a igualdade de acesso ao conhecimento. Sobre a divisão entre trabalhadores intelectuais e trabalhadores braçais o autor atesta:

Todos os homens são intelectuais, poder-se-ia dizer então: mas nem todos os homens desempenham na sociedade a função de intelectuais. Quando se distingue entre intelectuais e não-intelectuais, faz-se referência, na realidade, tão-somente á imediata função social da categoria profissional dos intelectuais, isto é, leva-se em conta a direção sobre a qual incide o peso maior da atividade profissional específica, se na elaboração intelectual ou se no esforço muscular-nervoso. (...) Em suma, todo homem, fora de sua profissão, desenvolve uma atividade intelectual qualquer, ou seja, é um "filósofo", um artista, um homem de gosto, participa de uma concepção do mundo, possui uma linha consciente de conduta moral, contribui assim para manter ou para modificar uma concepção do mundo, isto é, para promover novas maneiras de pensar. (GRAMSCI, 1982, p. 07). 
A ideia de uma educação pensada para "aqueles com capacidade culta" e outra, oposta, para "aqueles desprovidos desta capacidade" seria a prova de que a educação da época servia aos ideais da classe dominante, renegando à classe operária o papel de coadjuvante na fundamentação teórica da sociedade. A posição de Gramsci, nesse sentido, é de que todos somos dotados de competências para a intelectualidade e capazes de pensarmos nosso próprio meio. Em consonância com o pensamento marxista, o autor destaca o papel revolucionário do proletariado e defende que uma educação nos moldes de uma verdadeira democracia teria como consequência uma harmonia social, uma vez que estariam dissolvidas as classes sociais e, assim, a desigualdade. A inserção da educação nas teorias de inspiração marxista foi um marco gramsciano ao tema. Sua meta era a de romper com uma educação dualista, discriminatória e viciosa, pressupondo uma escola capaz de diluir as diferenças de classes e de estabelecer um currículo humanista e conciliador com as necessidades técnicas de produção. Conforme Ramos (1996), é desta escola que emergirá aquele cidadão completo e participante, consciente de sua função no âmbito da sociedade. Um sujeito autônomo e de consciência de sua posição de ação no mundo.

Sua influência pode ser sentida, inclusive, em nosso contexto brasileiro. Não à parte das principais questões que movimentavam a filosofia, o Brasil também enfrentou suas próprias dificuldades históricas que incitaram mudanças e transformações. A ditadura militar marcou um período de profunda repressão, mas também uma constante luta de resistência por parte de uma parcela numerosa da população. Nesta esteira, instaurou-se um novo momento para repensar as práticas educativas tradicionais e revisitar os objetivos da educação formal. A filosofia no Brasil florescia em sua faceta política e pedagógica, tratando de conceitos que deveriam servir mais do que somente para a discussão teórica, seriam a própria práxis sendo implantada no seio de nossa sociedade.

\section{Escola, espaço para a autonomia e conscien- tização}

Para este recorte, como destacamos anteriormente, selecionamos dois autores importantes para o cenário nacional e de grande relevância ao tema deste artigo. São eles: Paulo Freire (1921-1997), que se destacou ao promover uma escola com objetivo de ensinar para a leitura, interpretação $e$ transformação do mundo; e Dermeval Saviani (1943), ainda presente e ativo no cenário pedagógico, que voltou sua atenção para os conteúdos da educação e defendeu as suas devidas contextualizações a partir da realidade do aluno, como forma de inclusão social. Vejamos um pouco mais das contribuições filosóficas de cada um.

Para Freire a conscientização do educando seria o legado educacional prioritário, partindo da premissa indubitável de que vivemos em uma sociedade de extrema desigualdade e de carências sociais em diversos âmbitos. A liberdade, nesse sentido, é uma ideia política cunhada na noção de um desfavorecimento contínuo como condicionante de uma reprodução cíclica da condição de opressão. Sua preferência pelo termo educando revela sua visão de que o conhecimento não pode ser meramente transmitido, 
é preciso que se estabeleça em uma relação dialética sempre considerando as experiências e conhecimentos do próprio estudante neste processo. Assim, é na ideia de liberdade que sua pedagogia se apoia. Como explica Weffort na introdução da obra de Freire, educação como prática da liberdade,

A visão da liberdade tem nesta pedagogia uma posição de relevo. É a matriz que atribui sentido a uma prática educativa que só pode alcançar efetividade e eficácia na medida da participação livre e crítica dos educandos. É um dos princípios essenciais para a estruturação do círculo de cultura, unidade de ensino que substitui a escola, autoritária por estrutura e tradição. (1983, p.05) (...) Aqui a idéia da liberdade não aparece apenas como conceito ou como aspiração humana, mas também interessa, e fundamentalmente, em seu modo de instauração histórica. Paulo Freire diz com clareza: educação como prática de liberdade. Trata-se, como veremos, menos de um axioma pedagógico que de um desafio da história presente. Quando alguém diz que a educação é a afirmação da liberdade e toma as palavras a sério -isto é, quando as toma por sua significação real -se obriga, neste mesmo momento, a reconhecer o fato da opressão, do mesmo modo que a luta pela liberdade. (1983, p.07)

Uma ação pedagógica que desconsidere a liberdade como passo primeiro para a relação do conhecimento desfavorece o aluno em suas próprias competências de leitura $e$ interpretação de mundo. Esse tipo de ensino está sempre fadado a ser opressivo e ideológico, na medida em que considera o aluno apenas como receptáculo de um conhe- cimento já interpretado anteriormente. Esta questão implica um princípio fundamental para Freire. Segundo ele o educando carrega consigo uma bagagem cultural de seu próprio meio que não deve ser considera em critérios de melhor ou pior em relação à bagagem de seu professor. Em sala de aula a premissa da liberdade opera como garantidora de um aprendizado conjunto que, por sua vez, é a condição de possibilidade para a conscientização do aluno. Conscientizar é dar as ferramentas de análise para que cada indivíduo possa se localizar no mundo e perceber seu papel na transformação do mesmo. Sua filosofia tem como consequência uma tomada de consciência que deve partir da educação, não como ideologia de massa mas, antes, como fomentadora da reflexão crítica livre, autônoma e engajada. Weffort esclarece a definição acerca da conscientização,

Conscientização não significa, de nenhum modo, ideologizar ou propor palavras de ordem. Se a conscientização abre caminho à expressão das insatisfações sociais é porque estas são componentes reais de uma situação de opressão; se muitos dos trabalhadores recém-alfabetizados aderiram ao movimento de organização dos sindicatos é porque êles próprios perceberam um caminho legítimo para a defesa de seus interêsses e de seus companheiros de trabalho. (1983, p.12)

Ideologia é uma atitude de repressão, enquanto conscientização é sempre um espaço de autonomia. Esse grifo se faz muitíssimo importante nos dias atuais, já que em nosso contexto político presente uma parcela da sociedade se recusa a enxergar as diferenças entre uma educação para a liberdade e uma educação para a sujeição. No espaço 
de liberdade apontado por Freire três momentos são de suma importância para o bom fazer pedagógico neste critérios. O primeiro é aquele em que o educador se inteira daquilo que seu aluno conhece, como forma de trazer a cultura do aluno para dentro do espaço de aprendizagem; facilitando a compreensão do aluno, partindo sempre daquilo que é conhecido por este. O segundo é o momento de explorar as questões geradas durante as discussões, favorecendo a organização do conhecimento. No último passo temos a aplicação deste conhecimento gerado, culminando num espaço de problematização do tema. Esses três passos têm como objetivo garantir uma formação para a autonomia, para aquilo que a filosofia também chamou de emancipação.

A principal diferença entre a visão freireana da educação e a pedagogia tradicional está pautada nesta visão de aluno enquanto educando livre e de conhecimentos prévios e valiosos. Trata-se de uma valorização daquilo que sempre foi marginal na história das nossas sociedades brasileiras: a pobreza. Destacar a classe menos favorecida da sociedade e lhe dar status de protagonista foi uma novidade contemporânea que até hoje não foi bem digerida por uma parcela classista da população brasileira. A confiança de Paulo Freire está na força da reflexão de si, por cada sujeito empoderado neste processo educacional. Segundo o autor, é a autorreflexão "que as levará ao aprofundamento conseqüente de sua tomada de consciência e de que resultará sua inserção na História, não mais como espectadoras, mas como figurantes e autoras" (FREIRE, 1983, p.36). A filosofia brasileira opera com os conceitos trazendo-os para dentro de suas próprias necessidades. O conceito de autonomia como liberdade e o de emancipação enquanto conscientização acentua as temáticas caras para o nosso contexto.

Saviani também pensa de acordo com estas questões, focando sua preocupação em uma democratização do ensino enquanto prioridade para uma reestruturação social. A marginalidade daqueles sujeitos renegados ao papel subalterno da sociedade não pode ser reproduzida na educação; é preciso garantir o acesso e o aprendizado, e os conteúdos precisam refletir essa preocupação. $\mathrm{O}$ conhecimento deve estar nivelado levando em conta o antigo e o novo, os conhecimentos acumulados e a inovação. Segundo Saviani,

Uma pedagogia articulada com os interesses populares valorizará, pois, a escola; não será indiferente ao que ocorre em seu interior; estará empenhada em que a escola funcione bem; portanto, estará interessada em métodos de ensino eficazes. Tais métodos se situarão para além dos métodos tradicionais e novos, superando por incorporação as contribuições de uns e de outros. Portanto, serão métodos que estimularão a atividade e iniciativa dos alunos sem abrir mão, porém, da iniciativa do professor; favorecerão o diálogo dos alunos entre si e com o professor mas sem deixar de valorizar o diálogo com a cultura acumulada historicamente; levarão em conta os interesses dos alunos, os ritmos de aprendizagem e o desenvolvimento psicológico mas sem perder de vista a sistematização lógica dos conhecimentos, sua ordenação e gradação para efeitos do processo de transmissãoassimilação dos conteúdos cognitivos. (1999, p.79)

Uma educação para a emancipação, nesse sentido, jamais poderia ser acusada de 
menos rigorosa em seus conteúdos. Garantir o aprendizado e estar preocupado e atento paras as carências e diferenças entre os alunos não é o mesmo que ser omisso ou menos preocupado com a qualidade da educação. A diferença está no olhar da educação para com o aluno, em especial para aquela parcela que foi historicamente deixada de lado, com menos acesso e mais dificuldade de permanência. No ensino superior, por exemplo, essa ideia corrobora para a noção de que não basta a democratização do acesso, é preciso garantir a permanência deste aluno e prezar pela qualidade do que se é ensinado. Esta é a verdadeira equidade no âmbito social, não a mera fachada das oportunidades. No quesito ideologização Saviani também nos aponta algumas questões pertinentes. Segundo escreve,

De uns tempos para cá se tornou lugar comum a afirmação de que a educação é sempre um ato político. Mas o que significa essa afirmação? Obviamente, trata-se de um "slogan" que tinha por objetivo combater a idéia anteriormente dominante segundo a qual a educação era entendida como um fenômeno estritamente técnico-pedagógico, portanto, inteiramente-autônomo e independente da questão política. Nesse sentido o "slogan" cumpriu uma função cuja validade se-inscreve nos limites da "teoria da curvatura da vara". Com efeito, se a vara havia sido curvada para o lado técnico-pedagógico, o referido "slogan" forçou-a em direção ao pólo político. Com isto, entretanto, corre-se o risco de se identificar educação com política, a prática pedagógica com a prática política, dissolvendo-se, em conseqüência. a especificidade do fenômeno educativo. (1999, p. 91)
Compreendemos que educação pode ser uma faceta política, mas esta jamais pode ser a finalidade última de sua ação. É sabido que todas as práticas educacionais deste olhar acolhedor e humano determinam uma prática política dentro da sociedade, uma vez que um sujeito consciente interage com seu meio de maneira ativa e não mais passiva em relação ao mundo ao seu redor. Mas simplificar este pensamento enquanto uma finalidade política de interesse determinado é uma redução demasiadamente simples e descomprometida. A filosofia empregada aqui é prática e teórica ao mesmo tempo, girando numa engrenagem de açãopensamento-ação que opera, se insere $e$ transforma.

Saviani pensou acerca de conceitos como democracia e marginalidade, assumindo uma postura decisiva enquanto educador e pensador brasileiro. Freire abriu definitivamente as portas para estas ideias, inaugurando um cenário revitalizado para o fazer pedagógico e para as teorias educacionais.

\section{O legado sempre atual}

A filosofia brasileira se constituiu a partir de muitos aspectos, tendo tido destaque neste trabalho o que tange as reflexões $e$ práticas no âmbito educacional. Não somente os autores citados, mas tantos outros, contribuíram para uma visão pedagógica renovada que até hoje se faz presente no nosso modelo educacional. É verdade que a prática ainda encontra muitos desafios, mas muitas de nossas máximas contemporâneas se pode, em grande parte, atribuir ao esforço destes grandes filósofos brasileiros. 
A pedagogia contemporânea não mais relaciona professor e educando em termos de oposição; de um lado aquele detentor do conhecimento e, de outro, aquele a quem o conhecimento é repassado de forma passiva. A escola não é mais vista como espaço de mera educação do corpo e do decorar de conteúdos. A classe baixa não é mais tida como sem cultura e desprovida de conhecimentos prévios interessantes. A educação não mais objetiva "separar o joio do trigo", favorecendo apenas aqueles mais providos de condições financeiras e de acesso cultural. Se hoje é possível fazer tais afirmações e encontrar um número expressivo de educadores que concordem com elas, é graças ao pensamento filosófico educacional dos autores que trabalhamos anteriormente. E com eles outros muitos, que motivados pelo contexto político brasileiro, expressam uma filosofia capaz de sustentar uma mudança real e estrutural de nosso fazer pedagógico.

Tais ideias não somente influenciaram professores em sua visão individual, também serviram, e servem, de apoio teórico para a legislação brasileira acerca da educação. Não por acaso os textos e leis que versam sobre o tema se valem de expressões como "emancipação", "formação integral" $e$ "autonomia". Também não por acaso as questões de equidade e de condições aos menos favorecidos se torna discussão central da educação brasileira contemporânea, levando a uma série de políticas públicas para uma educação verdadeiramente democrática.

Por fim, este trabalho se propôs a um pequeno recorte da teoria de dois autores caros à nossa realidade, como forma de reforçar a tese de que temos uma produção filosófica pertinente em nosso país e que muito contribuiu para mudanças estruturais de nossa sociedade. Concluindo que é errôneo afirmar que não possuímos produção filosófica no Brasil.

\section{Referências}

BOTOMORE, T. Dicionário do pensamento marxista. $2^{\mathrm{a}}$ ed. Trad. Waltensir Dutra. Rio de Janeiro: Zahar, 2012.

FREIRE, P. Educação como prática da liberdade. 14a ed. Rio de Janeiro, Paz e Terra, 1983. GRAMSCI. A. Os intelectuais e a formação da cultura. 4 ed. Trad. Carlos Nelson Coutinho. Rio de Janeiro: editora civilização brasileira, 1982.

RAMOS, L. M. P. C. Educação e Trabalho: a Contribuição de Marx, Engels e Gramsci à Filosofia da Educação. In: Revista brasileira de estudos pedagógicos. Brasília, v.77, n.185, p.7-32, jan./abr.1996.

SAVIANI. D. Escola e democracia: teorias da educação, curvatura da vara, onze teses sobre educação e política. 32a ed. Campinas: Autores Associados, 1999. 
WEFFORT, F. C. Educação e política: reflexões sociológicas sobre uma pedagogia da Liberdade. In. Educação como prática da liberdade. 14ª ed. Rio de Janeiro, Paz e Terra, 1983.

Recebido em: 11/07/2020 Aprovado em: 17/10/2020 